\title{
DIFERENCIAS LÉXICAS ENTRE HISPANOAMÉRICA Y ESPAÑA: ANGLICISMOS VS. TÉRMINOS VERNACULARES
}

\author{
MIHAELA CIOBANU
}

Universidad de Bucarest

\begin{abstract}
Resumen: Los anglicismos están cada vez más presentes en casi todas las lenguas, penetrando en todos los campos y discursos. Además de los términos vernaculares que se emplean de modo general (ingeniero, profesor, etc.) y de los anglicismos generales, hay también términos vernaculares diferentes de un país a otro (contador (Arg.) vs. contable (Esp.)) como también anglicismos que tampoco son generales y que en la mayoría de los casos coexisten con los términos vernaculares, generales o específicos (jornada completa vs. full-time), lo cual no afecta a la intercomprensión. Nos centraremos para este análisis sobre todo en el campo laboral.
\end{abstract}

Palabras clave: anglicismos, términos vernaculares, variación, terminología

\begin{abstract}
Anglicisms are increasingly present in almost all languages, in all fields of activity and discourse categories. Besides native language terms of general use (ingeniero, profesor, etc.) and general Anglicisms, there are others which differ from one country to another (contador (Arg.) vs. contable (Esp.)). There are also Anglicisms which are not general and that in most cases coexist with native language terms, either general or specific (jornada completa vs. full time), which does not affect comprehension. This paper focusses on the analysis of the work-related field.
\end{abstract}

Keywords: Anglicisms, native language terms, variation, terminology

\section{Introducción}

El léxico es donde se muestra patente la diferencia entre el español peninsular y el español de América y también entre las diferentes variedades del español americano, dado que aquí tampoco hay unidad. El léxico es vivo y por eso cambia constantemente, se recuperan significados ya olvidados o se adoptan otros nuevos.

Los diccionarios ofrecen datos y materiales léxicos valiosos, pero también la lengua en uso nos pone a disposición este tipo de informaciones.

El presente trabajo trata sobre las diferencias léxicas entre Hispanoamérica y España, el análisis de los términos y sintagmas utilizados en el campo laboral, 
Diferencias léxicas entre Hispanoamérica y España: anglicismos vs. términos vernaculares

con una especial atención en los anglicismos y en los términos vernaculares empleados en este campo.

Chris Pratt define el concepto de anglicismo como "[...] elemento lingüístico, o grupo de los mismos, que se emplea en el castellano peninsular contemporáneo y que tiene como étimo inmediato un modelo inglés" (1980:115). El mismo autor identifica dos variedades de anglicismos: anglicismo patente "toda forma identificable como inglesa, o bien totalmente sin cambiar (como ranking, hippy, sidecar), o bien adaptada, parcial o totalmente, a las pautas ortográficas del español contemporáneo (por ejemplo boicot, boxear, travelín)" (Pratt, 1980:116) y anglicismo no patente "aquellos anglicismos que se reconocen como formas españolas" (Pratt, 1980:160).

Para realizar el análisis hemos consultado sitios de ofertas de trabajo (www.computrabajo.com). El corpus viene representado por este sitio en tres versiones (España, Argentina y México) para ver las coincidencias y las diferencias que se utilizan en cada país. Hemos optado por elegir este sitio porque las ofertas de trabajo son las mejores muestras para comprobar el léxico laboral actual y la frecuencia de uso de ciertos términos en los países anteriormente mencionados.

Este trabajo trata no solamente de palabras empleadas exclusivamente en los países mencionados, sino también de preferencias, mayor densidad y frecuencia de uso en los respectivos países. Tampoco podríamos decir que solamente éstos se emplean. No es un estudio exhaustivo, tratándose de ofertas de trabajo que, tal como nos podemos dar cuenta, aparecen y desaparecen cada día, "huecos profesionales" que se quieren cubrir en algún momento. Pero al elegir esta modalidad, quisimos presentar una muestra de léxico vivo, más o menos controlado, que de este modo refleja la realidad lingüística bajo investigación.

Para que el análisis sea más fácil y más productivo y concluyente hemos decidido optar por este sitio web con las tres versiones dado que tienen la misma arquitectura. El período de investigación fue de tres meses, puesto que cada día aparecen y desaparecen ofertas. Como el sitio es muy amplio, con ofertas de toda índole, se ha vuelto necesario restringir el área y hemos filtrado las ofertas en función de varios sectores. Después de consultar la división sectorial del sitio, hemos elegido analizar en comparación las categorías coincidentes en los tres sitios web: hostelería/turismo, economía/contabilidad/finanzas, medicina/salud, administración/oficina, informática/ telecomunicaciones y legal/asesoría. 
Las ofertas de trabajo consultadas varían también en cuanto al número. En total, en los seis sectores analizados: en España 883 anuncios, en Argentina 9552 y en México, 27935.

A nivel general de las ofertas de trabajo, cuando se indica la pertenencia del oficio al sector de actividad, se emplean fórmulas específicas preferentes: (España) sector, área (“...importante compañía del sector energético...", "¿'Tienes experiencia en el área administrativa?"); (Argentina) rubro (“...con experiencia en el rubro gastronómico"); (México): ramo, giro ("...empresa líder en el ramo del entretenimiento..."; “...importante empresa del giro restaurantero...”).

Igualmente, en lo que atañe al nivel de estudios solicitado en las ofertas, hay también diferencias léxicas en cuanto a estos requisitos: (España) graduarse/graduado, titularse/titulado, licenciarse/licenciado ("...selecciona Licenciado/a o Graduado/a en medicina..." ); (Argentina) recibirse/recibido ("Estamos en la búsqueda de un contador recién recibido o próximo a recibirse para cubrir el puesto de analista contable"2); (México) egresar/egresado ("Importante banco a nivel mundial solicita: auxiliar contable «Recién egresados»...” $)$.

En lo referente a la tipología de jornada laboral, además de los sintagmas españoles empleados en cada país, se nota la alternancia de éstos con los anglicismos full time y part time. Si en España el uso de estos anglicismos es bastante reducido, en Argentina se nota una preferencia mayor que en México por utilizar estos sintagmas (casi se emplean más los anglicismos que los sintagmas españoles).

\footnotetext{
${ }^{1}$ http://www.computrabajo.es/bt-ofrd-grupoadecco-33945852.htm?BqdPalabras=graduado (Fecha de consulta: 9 de noviembre de 2017).

2 https://www.computrabajo.com.ar/ofertas-de-trabajo/oferta-de-trabajo-de-analista-contableadministrativo-contador-jr-en-caballito-60ED128B793875BC (Fecha de consulta: 27 de octubre de 2017).

3 https://www.computrabajo.com.mx/ofertas-de-trabajo/oferta-de-trabajo-de-auxiliarcontable-recien-egresados-en-xochimilco-5942B556A49951A8 (Fecha de consulta: 4 de noviembre de 2017).
} 
Diferencias léxicas entre Hispanoamérica y España: anglicismos vs. términos vernaculares

España

tiempo completo
medio tiempo
jornada parcial
media jornada

Argentina

jornada completa

jornada reducida

jornada partida

medio turno

media jornada

borario cortado

borario corrido
México

tiempo/ turno completo

medio tiempo/turno

También, los turnos laborales se identifican de manera diferente y preferente. Además de turno de mañana, turno de tarde, turno de noche/ nocturno y turno de día/diurno, en Hispanoamérica, sobre todo en México, se nota una frecuencia mayor de uso de los sintagmas turno matutino y turno vespertino. Las personas que trabajan en turnos, en Argentina vienen identificadas como turnante ("recepcionista turnante"), y los turnos pueden ser rotativos (en México se prefiere turnos rolados).

Para referirse a los días libres, días sueltos (Esp.) o días de descanso (Méx.), en Argentina los llaman francos ("...amplia disponibilidad horaria de lunes a sábado, con franco los domingos."). De esta base se ha formado el sust./adj. franquero/a, muy utilizado en las ofertas de trabajo de Argentina, aplicable para cubrir los días libres del personal de plantilla (recepcionista franquero, conserje franquero, cocinera franquera, etc.). Otra modalidad expresada a través de una creación acronímica, específica para Argentina, es (turno) sadofe (SADOFE: Sábados, Domingos y Feriados). En México se utiliza cubreturno.

Acerca de la tipología de los contratos de trabajo, se notan también diferencias a nivel léxico:

España

contrato (de trabajo) por tiempo

indefinido

contrato de trabajo a tiempo parcial

contrato para obra o servicio

determinado/temporal
Argentina

contrato (de trabajo) por tiempo indeterminado

contrato de trabajo a plazo

fijo/determinado

contrato (de trabajo) eventual

\section{México}

contrato (de trabajo) por tiempo indeterminado contrato de trabajo para tiempo determinado contrato por/para obra

${ }^{4} \mathrm{El}$ DRAE lo indica aplicable a los deberes de carácter militar “[...] 11. Exento de servicio, libre de obligación o trabajo en deberes de carácter militar”. 
La influencia del inglés se nota también en el léxico general empleado en las ofertas de trabajo: aplicar (Arg.) ("Los interesados aplicar CV solo con experiencia en el puesto"), reporte/reportar (Arg., Méx.) ("Responsable directo de las ventas y reportes financieros [...]"; "[...] la posición reporta al jefe de Tesorería [...]"), chequear/checar (Méx.) (“[...] checar y realizar reportes [...]”).

\section{Hostelería/turismo}

La elección de esta categoría radica en la presencia del turismo como una rama de la economía muy difundida en la sociedad actual.

Los anglicismos están cada vez más presentes en casi todas las lenguas, penetrando en todos los campos y discursos. El turismo no hace caso omiso, siendo uno de los campos donde más penetran los extranjerismos.

Además de los términos vernaculares que se emplean de modo general en el ámbito hispánico (agente de viajes, cocinero/a, gobernanta, guia, panadero/a, pastelero/a, repostero/a, recepcionista, etc.), hay también términos específicos de este campo que presentan diferencias diatópicas (regionales) en el mundo hispanohablante, conceptos que suelen expresarse en América mediante un vocablo distinto del empleado en la Península:

\begin{tabular}{|c|c|c|}
\hline España & Argentina & México \\
\hline camarero/a de pisos & $\begin{array}{l}\text { mucamo/a } \\
\text { camarero/a (menos utilizado) }\end{array}$ & $\begin{array}{l}\text { camarero/a } \\
\text { recamarero/a } \\
\text { camarista } \\
\text { recamarista }\end{array}$ \\
\hline camarero/a (de bar, de res- & mesero/a & mesero/a \\
\hline taurante, de sala, de banquete) & barman, barwoman & cantinero/a \\
\hline bartender (var. barténder) & barista & fuentero/a \\
\hline barman, barwoman & cafetero/a & barista \\
\hline barista & mozo de salón & $\begin{array}{l}\text { bartender } \\
\text { barman, barwoman }\end{array}$ \\
\hline ayudante de camarero & $\begin{array}{l}\text { ayudante de camarero } \\
\text { runner }\end{array}$ & $\begin{array}{l}\text { garrotero / a (ayudante de } \\
\text { mesero - restaurante) } \\
\text { charolero / a (ayudante de } \\
\text { mesero - cafetería) }\end{array}$ \\
\hline jefe de camareros & supervisor de camareros & capitán de meseros \\
\hline
\end{tabular}


Diferencias léxicas entre Hispanoamérica y España: anglicismos vs. términos vernaculares

$\begin{array}{lll}\text { friegaplatos (var. fregaplatos) } & \text { bachero/a } & \text { lavaplatos } \\ \text { lavaplatos } & \text { lavacopas } & \text { steward } \\ \text { ayudante de cocina } & \text { lavavajillas } & \text { lavaloza(s) } \\ & \text { peón de limpieza } & \text { auxiliar de limpieza } \\ \text { botones } & \text { botones } & \text { botonero } \\ \text { lobby assistant } & \text { bellboy } & \text { concierge } \\ \text { conserje } & \text { maletero } & \text { bellboy } \\ & & \text { mozo (de equipaje) }\end{array}$

Hemos identificado alternancias entre sintagmas en inglés y sintagmas en español: lobby assistant/bell-boy vs. botones, mozo; wedding planner vs. coordinador de bodas/eventos; hostess vs. azafato/a, edecán (Méx.); check-in vs. facturación; booking vs. reserva; ticketing vs. billetaje; room-service vs. servicio de habitaciones, servicio de cuarto, servicio a la habitación; guest service vs. servicio a buéspedes; barman/barwoman vs. camarero/a; butler vs. mayordomo; doorman vs. portero, etc., como también variación en español en designar la misma realidad turística: (Esp.) billete / pasaje de avión - (Am.) boleto / pasaje de avión; (Esp.) billetería - (Am.) boletería; (Esp.) billetaje - (Am.) boletaje; (Esp.) llegadas y salidas - (Am.) arribos y partidas; (Esp.) reserva - (Am.) reservación; (Esp.) facturar equipaje - (Am.) documentar equipaje; (Esp.) tarjeta de embarque - (Am.) pase de abordar; (Esp.) sala de embarque - (Am.) sala de abordaje; (Esp.) pernoctación (Am.) pernocta; (Esp.) socorrista - (Am.) guardavidas / salvavidas; (Esp.) estancia (Am.) estadía; (Esp.) alquilar - (Am.) rentar, etc.

\section{Economía/contabilidad/finanzas}

En este sector, además de los términos empleados de manera unitaria (analista contable, asesor/a, cajero/a, gestor de cuentas, técnico contable, etc.), hay también vocablos específicos (se trata de frecuencia y no de uso exclusivo):

$\begin{array}{lll}\text { España } & \text { Argentina } & \text { México } \\ \text { oficina contable } & \text { estudio contable } & \text { despacho contable } \\ \text { contable } & \text { contador } & \text { contador } \\ \text { contabilidad } & \text { contaduría } & \text { contaduría } \\ \text { pedido } & \text { pedido } & \text { pedido, pedimento } \\ \text { mercancía } & \text { mercadería } & \text { mercadería } \\ \text { cálculo } & \text { conteo } & \text { conteo } \\ \text { promotora inmobiliaria } & \text { desarrolladora inmobiliaria } & \text { desarrolladora inmobiliaria } \\ \text { oficina de crédito } & \text { buró de crédito } & \text { buró de crédito, círculo de crédito }\end{array}$


alquiler de coches alquiler de autos al por mayor/al por menor arrendamiento de vehiculos/autos al menudeo/al mayoreo

Hay también diferencias léxicas en Hispanoamérica (presentamos las preferencias de uso): (Méx.) nominista (especialista en nóminas, cálculo de nóminas); (Arg., Méx.) facturista (administración y control del proceso de facturación y carga de pedidos); (Méx.) diligenciero/a (diligenciar a bancos, depósitos bancarios); (Arg., Méx.) tesorero/a (confeccionar los objetivos anuales del área de la tesorería); (Méx.) fiscalista (profesional especializado en el área fiscal); (Arg., Méx.) inventarista (conteo de mercadería en grandes tiendas y supermercados), etc.

En Hispanoamérica se utiliza más contador que contable (contador administrativo, contador de impuestos, contador auxiliar, contador financiero, contador fiscal, etc.), éste último siendo empleado más en sintagmas especializados, como adjetivo: estudio contable, área contable, administrativo contable, analista contable, ayudante contable, etc.

También, a nivel general, alterna el anglicismo controller con contador/contable, staff (“...busca incorporar a su staff...") alterna con equipo (“... busca incorporar a su equipo..."), cold calling con llamada en frio ${ }^{5}$, o se prefieren solamente los anglicismos ya consagrados por el uso: broker (o bróker-adaptado a la pronunciación española), etc.

En la descripción de los puestos de trabajo específicos de este sector se emplean los adjetivos junior (júnior viene también registrado en el DRAE con esa acepción laboral: Inferior en categoría y experiencia a quienes desempeñan la misma profesión o cargo), senior (sénior: Superior en categoría y experiencia a quienes desempeñan la misma profesión o cargo) y SSR (Semi Senior): analista contable senior, consultor senior, contador público senior, analista contable junior, contador junior, auxiliar contable junior, analista administrativo contable SSR, etc.

5 https://www.computrabajo.com.ar/ofertas-de-trabajo/oferta-de-trabajo-de-activadoracomercial--zona-pilar--en-pilar-CF2F1E2BEF0EBD83 (Fecha de consulta: 8 de noviembre de 2017).

6 júnior. Voz procedente del comparativo latino iunior ('más joven'), cuyo uso actual en español se ha revitalizado por influjo del inglés junior. [...] Referido a un profesional, 'de menor edad y, por tanto, con menos experiencia que otro'. A veces designa al profesional de menor rango, independientemente de su edad. [...] Se opone a sénior. (Diccionario Panhispánico de Dudas). 
Diferencias léxicas entre Hispanoamérica y España: anglicismos vs. términos vernaculares

\section{Medicina/salud}

En este sector las diferencias son bastante reducidas. Hay términos de uso general (cirujano/a, dermatólogo/a, enfermero/a, farmacéutico/a, logopeda, médico/a, oftalmólogo/a, pediatra, podólogo/a, psiquiatra, radiólogo/a, etc.), pero también existen variaciones:

$\begin{array}{lll}\text { España } & \text { Argentina } & \text { México } \\ \text { informe médico } & \text { reporte médico/informe médico } & \text { reporte médico/informe médico } \\ \text { nutricionista } & \text { nutriólogo } & \text { nutriólogo } \\ \text { protésico dental } & \text { mecánico dental, protesista (dental) } & \text { técnico dental } \\ \text { terapeuta } & \text { terapista } & \text { terapista } \\ \text { optometrista } & \text { optómetra, optometrista } & \text { optometrista } \\ \text { cosmetólogo/a } & \text { cosmiatra } & \text { cosmeatra/cosmiatra } \\ \text { cosmetología } & \text { cosmiatría } & \text { cosmeatría/cosmiatría } \\ \text { flebotomista/venopuncionista } & \text { extraccionista } & \text { flebotomista/venopuncionista }\end{array}$

Se dan también variaciones que se emplean de modo general en español: médico/a laboral - médico/a del trabajo; clínica dental - gabinete estomatológico - gabinete odontológico - gabinete dental - centro de salud oral; estomatólogo - dentista; urgenciólogo médico general urgencias; enfermera - cuidadora; kinesiólogo - quinesiólogo, etc. y creaciones léxicas específicas de este sector: admisionista (persona que trabaja en el área de admisión de pacientes en un centro médico).

\section{Informática/telecomunicaciones}

Términos sectoriales unitarios: analista, diseñador/a web, informático/a, ingeniero/a, operador/a, programador/a, técnico de redes, etc.

La informática es otro de los sectores donde se emplean mucho los anglicismos: tester, blogger, software, hardware, outsourcing, etc., pero hay también variaciones/calcos léxicos: desarrollador - developer; programador - programmer; analista - analyst; mesa de ayuda help desk; mesa de servicio(s) - service desk; centro de llamadas - call center; base de datos - data base; analista de negocio - business analyst; ingeniero en informática - ingeniero informático, etc. 
Además de estas variaciones con los anglicismos, se dan también variaciones dentro del español: (Esp.) informática - (Am.) computación; (Esp.) ordenador - (Am.) computadora; (Esp.) móvil - (Am.) celular; (Esp.) técnico informático - (Am.) técnico en computación; (Esp.) sistemas informáticos - (Am.) sistemas computacionales, etc., y creaciones léxicas típicas del sector: capturista (Méx. persona que trabaja haciendo acopio de datos a través de un ordenador), cadista (Méx. dibujante en AutoCAD), y otras a base de los anglicismos: desarrollador cloudera, etc.

Las siglas y los acrónimos se emplean aquí con más densidad que en otros sectores: SAP (System, Application and Products), SAP PI/PO (System, Application and Products Process Integration / Purchase Order), ABAP (Advances Business Application Programming), ERP (Enterprise Resource Planning), JAVA, iOS, etc.

\section{Administración/oficina}

Términos comunes: administrativo/a, agente de ventas, analista, asesor, auxiliar administrativo, recepcionista, secretaria, teleoperador/a, etc. y variaciones:

$\begin{array}{lll}\text { España } & \text { Argentina } & \text { México } \\ \text { formación } & \text { capacitación } & \text { capacitación, entrenamiento } \\ \text { carné de conducir } & \begin{array}{l}\text { carnet de conductor / carnet de } \\ \text { conducir / licencia de conducir / }\end{array} & \text { licencia de conducir / licencia de chófer } \\ & \text { registro de conducir } & \text { ingresos y egresos } \\ \text { ingresos y gastos } & \text { ingresos y egresos } & \text { ramo/giro/sector automotriz } \\ \text { sector automóvil } & \text { empresa funeraria } \\ \text { funeraria / empresa de } & \text { rubro automotriz } & \end{array}$

También hemos identificado términos sectoriales específicos que cuentan con preferencia de uso en función del país. Por ejemplo, en México: capturista (captura de información); validador / escaneador (digitalizar documentos, revisión de documentos); nominista (elaboración de nóminas); facturista (elaboración de facturas, facturación); ajustador (verificar y actualizar base de datos); monitorista (seguimiento de monitores de diferentes sucursales, elaboración de reportes, controles internos); estimacionista/estimador (elaboración de estimaciones), etc. En Argentina: adicionista (atención al cliente, organizar eventos, control de proveedores, etc.); capacitador (profesional que se encarga de la capacitación); inventarista (realizar 
Diferencias léxicas entre Hispanoamérica y España: anglicismos vs. términos vernaculares

inventarios, conteo de mercadería); tipeo (de tipear - to type); presupuestista (elaborar presupuestos), etc.

\section{Legal/asesoría}

Términos comunes: abogado/a, agente inmobiliario, asesor/a, consultor/a, gestor, etc. y también variaciones:

$\begin{array}{lll}\text { España } & \text { Argentina } & \text { México } \\ \text { despacho de abogados } & \text { estudio jurídico / despacho de } & \text { despacho de abogados / firma de } \\ & \text { abogados / estudio de abogacia } & \text { abogados / bufete jurídico / } \\ & & \text { despacho jurídico } \\ \text { notaría } & \text { escribanía } & \text { notaría } \\ \text { notario/a } & \text { escribano/a } & \text { notario/a }\end{array}$

En este sector también hemos identificado variaciones y términos preferentes: abogado procesalista - abogado litigante, archivista - archivero - archivólogo, carpetista (Arg. llevar la gestión de la carpeta de las escrituras), etc.

\section{Conclusiones}

En la derivación, la sufijación es el fenómeno más frecuente, los más productivos sufijos son -ista y -ero para la designación de agentes: adicionista, archivista, cadista, camarista, capturista, carpetista, facturista, fiscalista, inventarista, monitorista, nominista, nutricionista, presupuestista, recamarista, terapista, etc.; archivero, bachero, botonero, cafetero, cantinero, charolero, diligenciero, fiambrero, franquero, garrotero, mesero, pastorero, pastero, recamarero, tablajero, taquero, tesorero, volantero, etc., que presentan una gran vitalidad en el español actual.

Igualmente, presentan un grado mayor de integración en la lengua (gran parte no vienen registrados en los diccionarios consultados: bizcochero/a, cadenero, fiambrero/a, francesero/a, pastero/a, pastorero/a (derivado de "tacos al pastor", plato mexicano con influencia libanesa), pizzero/a, sandwichero/a, sushero/a, tablajero/a, taquero/a, tempurero/a, volantero/a, wafflero/a, etc.) a través del uso frecuente $\mathrm{y}$, también, de la transparencia, lo que facilita la identificación por los hablantes. 
Préstamos con sufijos españoles: piæzero (it. piæza + -ero), sandwichero (ingl. sandwich + -ero), sushero (jap. sushi + -ero), tempurero (jap. tempura + -ero), wafflero (waffle + -ero), etc.

La mayoría de los préstamos provienen del inglés: aplicar (to apply), chequear/checar (to check), proactivo (proactive), reporte (report), reportar (to report), desarrollador cloudera (cloud), etc.

Alternancia entre términos o sintagmas en inglés con sus equivalentes españoles, con variados grados de frecuencia (en el momento de nuestro estudio, por ejemplo, en Argentina se nota una preferencia mayor por utilizar los sintagmas full time y part time frente a jornada completa y jornada reducida): lobby assistant/bell-boy vs. botones, mozo; wedding planner vs. coordinador de bodas/eventos; hostess vs. azafata, edecán; check-in vs. facturación; booking vs. reserva; ticketing vs. billetaje; room-service vs. servicio de habitaciones, servicio de cuarto, servicio a la habitacion; guest service vs. servicio a buéspedes; barman/barwoman vs. camarero/a; butler vs. mayordomo; doorman vs. portero; desarrollador vs. developer; programador vs. programmer; analista vs. analyst; mesa de ayuda vs. help desk; mesa de servicio(s) vs. service desk; centro de llamadas vs. call center; base de datos vs. data base, etc.

Algunas de las profesiones fueron documentadas en una oferta o en unas cuantas, por lo tanto es imposible saber si todas las empresas identifican con el mismo vocablo la profesión en cuestión o si las tareas asignadas son las mismas.

Asimismo, encontramos dificultades a la hora de verificar todas las ofertas dado el gran número de anuncios consultados (hemos tomado en cuenta sólo las ofertas en español, hay también numerosos anuncios en inglés) y porque no todas las ofertas corresponden al sector donde aparecen publicadas (desde el punto de vista léxico de la investigación):

$\begin{array}{lccr}\text { Sector (10.10.2017) } & \text { España } & \text { Argentina } & \text { México } \\ \text { Turismo/hostelería } & 134 & 1095 & 4523 \\ \text { Informática/telecomunicaciones } & 204 & 4056 & 5156 \\ \text { Legal/asesoría } & 16 & 157 & 886 \\ \text { Economía/contabilidad/finanzas } & 93 & 1020 & 6214 \\ \text { Medicina/salud } & 100 & 1466 & 2634 \\ \text { Administración/oficina } & 336 & 1758 & 8522 \\ \text { Total } & 883 & 9552 & 27935\end{array}$


Diferencias léxicas entre Hispanoamérica y España: anglicismos vs. términos vernaculares

La investigación léxica en el área laboral actual se muestra muy interesante desde el punto de vista de la evolución de la sociedad y de cómo el léxico trata de satisfacer esa evolución, las exigencias y las preferencias de la sociedad.

El neologismo vivifica la lengua, sirve para renovar y enriquecer su léxico, actualizar elementos, dar cuenta de nuevas realidades, y en él se manifiestan todas las tensiones que tienen lugar en el interior del léxico (Álvar Ezquerra, 1999:49).

\section{Bibliografía}

Alcaraz Varó, Enrique - Hugues, Brian - Campos Pardillos, Miguel Ángel - Pina Medina, Victor Manuel - Alesón Carbonell, María Amparo. 2006. Diccionario de términos de turismo y ocio, Inglés - Español, Spanish - English. Barcelona: Ariel.

Álvar Ezquerra, Manuel. 1999. La formación de palabras en español. Madrid: Arco/ Libros S.L.

Asociación de Academias de la Lengua Española. 2010. Diccionario de americanismos. Madrid: Santillana.

Calvi, Maria Vittoria. 2006. Lengua y comunicación en el español del turismo. Madrid: Arco/Libros S. L.

Gómez Capuz, Juan. 2004. Los préstamos del español: lengua y sociedad. Madrid: Arco/Libros S. L.

Gómez Capuz, Juan. 2005. La inmigración léxica. Madrid: Arco/Libros S. L.

Martín Camacho, José Carlos. 2004. El vocabulario del discurso tecnocientifico. Madrid: Arco/Libros, S.L.

Medina López, Javier. 1996. El anglicismo en el español actual. Madrid: Arco/Libros S.L. Pratt, Chris. 1980. El anglicismo en el español peninsular contemporáneo. Madrid: Gredos.

Real Academia Española, Asociación de Academias de la Lengua Española. 2005. Diccionario panhispánico de dudas. Madrid: Santillana Ediciones Generales, S.L.

VV.AA. 2001. Diccionario de la Lengua Española, vigésima segunda edición, 2 tomos, Real Academia Española. Madrid: Espasa Calpe. 